Revista de la red interuniversitaria de estudios sobre las literaturas rioplatenses contemporáneas en Francia

\title{
Anexo I. El fondo Saer: preservación, organización, edición. Informe y reflexiones
}

Julio Premat

\section{OpenEdition}

\section{Journals}

Edición electrónica

URL: http://journals.openedition.org/lirico/230

DOI: $10.4000 /$ lirico.230

ISSN: 2262-8339

Editor

Réseau interuniversitaire d'étude des littératures contemporaines du Río de la Plata

\section{Edición impresa}

Fecha de publicación: 1 diciembre 2011

Paginación: 185-210

ISBN: 2-9525448-5-9

ISSN: 2263-2158

\section{Referencia electronica}

Julio Premat, «Anexo I. El fondo Saer: preservación, organización, edición. Informe y reflexiones », Cuadernos LIRICO [En línea], 6 | 2011, Publicado el 01 julio 2012, consultado el 15 septiembre 2020 URL : http://journals.openedition.org/lirico/230

\section{(c) (i) $9 \Theta$}

Cuadernos LIRICO está distribuido bajo una Licencia Creative Commons Atribución-NoComercialSinDerivar 4.0 Internacional. 


\title{
ANEXO I \\ EL FONDO SAER: PRESERVACIÓN, ORGANIZACIÓN, EDICIÓN. INFORME Y REFLEXIONES.
}

\author{
Julio Premat \\ Université Paris 8 - Laboratoire d'Études Romanes
}

\section{Herencias de escritores}

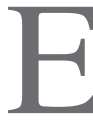

s una banalidad constatar que la muerte de un escritor transforma la percepción de sus textos. El fenómeno tiene particular trascendencia en el caso de la obra Saer, por el carácter siempre incompleto y en progresión de la serie de segmentos que la constituyen. El fin del sistema productivo cierra de manera paradójica esa serie, detiene el movimiento y crea una nueva perspectiva, que aunque siga caracterizándose por cierta inestabilidad, es panorámica y, con todas las restricciones del caso, completa. Pero no sólo en este sentido la desaparición física actúa e interviene sobre la obra; en Saer, como en tantos otros ejemplos, esa circunstancia biográfica abre las puertas a una nueva dimensión de su figura y de sus textos porque accedemos a los manuscritos, las notas preparatorias, los cuadernos, los esbozos, bocetos y borradores, o sea las trazas materiales de lo secreto, las etapas de producción de lo ya leído. Ese material, que será descrito y comentado en lo que sigue, tiene a la vez un valor digamos estético (estética cuya evaluación y dimensión merecerían una reflexión aparte) y genético, en la medida en que permite observar mecanismos de creación, transformando la visión coherente de la obra publicada al mostrar lo aleatorio, proliferante y accidental de la acumulación de textos que precede la edición de libros considerados definitivos.

De modo liminar, quizás no sea superfluo tomar cierta distancia crítica frente a la aparente naturalidad con la que familiares, universitarios y editores hacen circular-en bibliotecas, salas de remate, libros publicados y, últimamente, sitios web-, los papeles póstumos de un 
autor. Aunque por lo general se habla mucho al respecto, poco se escribe sobre las peripecias a las que da lugar una herencia literaria -de más está decir que tanto el término de "herencia", como el de "legado" son, en sí, simbólicamente significativos-. Antes de que los papeles de un escritor puedan llegar a tener algún tipo de accesibilidad (en una biblioteca o en alguna institución, por ejemplo, o gracias a publicaciones, más o menos parciales, más o menos respetuosas), se desencadena un proceso marcado por afectos, imaginario, ambiciones y rivalidades. Una verdadera construcción, que, a pesar de ser inevitable, no deja de ser un proceso que merece ser puesto de relieve. El proceso, aunque en sí magnifica las dificultades que presenta cualquier herencia y sería por lo tanto incluible en la esfera de lo privado, de hecho estructura, organiza y a su manera pretende determinar el sentido de lo que quedará, públicamente, del escritor fallecido, así como es un observatorio desde el que se vislumbran algunos rasgos de la ideología y del lugar atribuido a la literatura que son dominantes en un momento dado. $\mathrm{O}$, al menos, participa, a veces imaginariamente, en estos fenómenos.

Digresivamente, antes de presentar el "caso Saer", intentemos algunos ejemplos, mezclando información fehaciente con los insistentes rumores que circulan en el medio literario. Podríamos empezar por los casos de Proust y de Kafka, modélicos y legendarios en este nivel. Un Proust agonizante que transforma radicalmente el manuscrito de Albertina desaparecida, echando por la borda lo que algunos pretenden ser la cohesión de la Gran Obra, y por lo tanto traicionando su propia intencionalidad; o, como lo interpretan otros, marcando con un último gesto, un último suspiro escritural, un cambio que debe tomarse como un testamento, quizás críptico en una primera lectura, pero que podría descifrarse y cobrar sentido. ${ }^{1}$ O Kafka, decidiendo, también entre dos estertores agónicos, la destrucción de buena parte de su obra (otro "testamento), legado negativo que ha sido leído como una posición paradigmática ante la literatura, pero que así se piensa gracias a la bienvenida y tan comentada "traición" del "amigo fiel" (bis repetitia: otra "traición"). Los dos ejemplos apuntan a algunos tópicos, o inclusive mitemas. El primero es la de la intencionalidad, tan puesta en duda por la crítica del último siglo pero reactivada con vehemencia en estos casos: heredar supone poder descrifrar cuál era la intención del escritor, tanto con respecto a sus papeles póstumos como ante el conjunto de

\footnotetext{
${ }^{1} C f$. Nathalie Maurica Dyer, "Proust entre deux textes: réécriture et 'intention' dans Albertine disparue" en Paul Gifford et Marion Schmid (ed.), La Création en acte. Devenir de la critique génétique, Amsterdam/New York, Rodopi, 2007, pp. 83-96.
} 
su obra. La intención, que hoy consideramos ser una categoría incierta o inestable, se vuelve indiscutible cuando de legados se trata: ¿Proust quiso realmente alterar Albertina desaparecida o fue un intento fallido que su muerte impidió corregir? ¿Kafka pretendía que se destruyeran sus textos o ese pedido expresaba un momento de incredulidad ante la palabra literaria, a la vez en contradicción y coherencia frente a su trayectoria anterior? Una identificación digamos heroica con el escritor fallecido permite a los "herederos" responder a estos interrogantes con una autoridad que no admite réplicas, aunque la sombra de la traición pese, como hemos visto, en cada caso.

El segundo tópico es el del testamento. La herencia supone imperativos que hay que respetar, atribución de un poder sobre tal o cual parte de la obra, capacidad de decidir lo que se hace o no se hace y, en resumidas cuentas, otorga un derecho de propiedad, legal (fácilmente reconocida, casi siempre), pero también simbólica. Así, y volviendo a la intencionalidad, al testamento se lo fabrica retrospectivamente, atribuyendo a frases dispersas y a gestos supuestos del escritor el valor de voluntad e instrucción. Ahora bien, el testamento, como es sabido, es un texto con consecuencias legales, pero que se escribe y se lee como un texto de amor (o, al menos, de afectos). En estos casos, no hay en general un testamento escrito, pero los que se instalan en el lugar de los herederos fabrican ese texto y entran a menudo en conflicto entre sí -el amor es siempre exclusivo y la propiedad simbólica por definición fluctuante-. Como en las familias, siempre el campito del hermano tiene mejores pastos, papá nunca la quiso y ahora ella se quiere llevar todo, y el samovar del abuelo me tocaba a mí, que soy la hermana mayor, y no esta lámpara horrible que ni siquiera funciona. Lo mismo podría ampliarse, en lo que a escritores se refiere, a colectividades: todo escritor tendría que estar enterrado en su tierra natal (la nuestra), su biblioteca ser legada a una Biblioteca Nacional (la de una Nación cuyos símbolos reconocemos) y sus papeles integrar nuestro patrimonio nacional o provincial, etc. Ante el atractivo, digamos magnético y tradicional, del testamento, y frente a la ruptura que implica la muerte, muchos andamios teóricos y presupuestos críticos se derrumban. Piénsese, si no, que la necrología es uno de los únicos géneros que parece mantenerse idéntico a sí mismo, resistiendo a cualquier deconstrucción y repitiendo el panegírico, el lugar común y la codificación obsoleta.

En el espacio de la literatura latinoamericana, tenemos también nuestro ejemplo paradigmático, que es el de Borges. Su herencia fue, desde luego, un terreno disponible para apropiaciones imaginarias de 
parte de pálidos remedos del escritor y de mujeres (esposa, hermana, amigas, enamoradas virtuales) que creyeron lograr, por fin, poseer plenamente a ese hombre tan genial como inasible. Y aunque a él no se le ocurrió nada mejor que irse a morir en el extranjero, las anécdotas sobre la transmisión póstuma de intenciones y bienes desde Suiza pululan (hasta la versión grotesca de un crítico recibiendo, en un murmullo, esta frase del viejo sabio: "Lo condeno a ser la memoria de Borges"). Su herencia tampoco es comprensible sin, por supuesto, una canonización previa, ni sin aludir a ciertas concepciones sobre el saber de su autor y su intencionalidad, terrenos en los que las peripecias legales, editoriales y personales de su legado parecen contradecir, frontalmente, algunos postulados de la obra: piénsese, por ejemplo, en el valor exorbitante que alcanza cualquier manuscrito suyo en una subasta internacional. ${ }^{2}$ En el terreno de la edición asistimos a algo similar: no sólo Borges siguió publicando post-mortem, con un ritmo productivo envidiable, sino que esas publicaciones incluyen tanto textos explícitamente rechazados por él como textos menores, todo lo cual ha ampliado vertiginosa, aunque no siempre ventajosamente, lo que llamamos la "obra de Borges". Y los encarnizados conflictos que acompañaron la reedición de la versión francesa en la colección La Pléiade, más allá de ciertos excesos olvidables, se entienden tomando en cuenta los resabios de prestigio de las traducciones al francés y la aureola de consagración que mantiene la célebre colección en papel biblia de Gallimard: la herencia renueva, a cada paso, sus terrenos de discordia. En contraputno con esto, las condiciones de esta herencia particularmente compleja, impidieron, hasta el día de hoy, ediciones críticas serias y estudios genéticos exhaustivos.

Más brevemente, otros ejemplos: las exclusiones, odios, secretos, revelaciones y anatemas políticos que frenan la circulación de la obra de Felisberto Hernández; la saga de Adolfo de Obieta consultando vía el espiritismo a su padre para darle sentido a su papel de albacea y hasta de "autor" de la obra de Macedonio; las peripecias judiciales y editoriales que acompañan la herencia, en todos los sentidos caudalosa, de Adolfo Bioy Casares y Silvina Ocampo; la destrucción de los papeles, manuscritos y documentos de Antonio Di Benedetto por su esposa, cuando el escritor acaba de ser detenido por los militares y ella descubre un adulterio un poco más importante; la manera en que la homosexualidad sigue actuando como un secreto -a voces- o una

\footnotetext{
${ }^{2} C f$. Daniel Balderston, "Los manuscritos de Borges: imaginar una realidad más compleja que la declarada al lector", en Julio Premat (ed.), Arqueologías. Archivos, borradores, genealogías de escritura, Cuadernos LIRICO ${ }^{\circ}$ 7, en prensa.
} 
transgresión inaceptable que los herederos de Lezama Lima y de Puig se afanan en ocultar o en reprimir; la circulación azarosa, las manipulaciones y la censura a las que dio lugar el comprometedor diario de Alejandra Pizarnik antes de su publicación; la leyenda desarrollada en torno de la supuesta existencia de un "cuarto tomo" perdido que completaría y al mismo tiempo cerraría la obra de Juan L. Ortiz (leyenda en la que Saer en cierto modo participa y que motiva algunos aspectos de su novela La pesquisa); etc., etc. Los diferentes aspectos que subyacen en la lista arbitraria de ejemplos que precede sugieren que la herencia no es un bien existente que pasa de mano en mano, sino que se va articulando en tanto que relato, un relato significativo, ideológica y afectivamente. Con imprudencia, podría decirse que ese relato termina formando parte de la figura del autor y de sus leyendas. $\mathrm{Y}$, también, este relato debe integrarse como una modalidad extrema de un efecto de lectura y, para no ser ingenuos, reconozcamos que también revela el peso de intereses comerciales, de expectativas de carreras académicas y de otras instrumentalizaciones posibles de ese "muerto" en la circulación de la literatura.

Ahora bien, es fácil retomar críticamente el devenir del fondo de un escritor y discutir las decisiones de preservación y edición de herederos y albaceas; pero más allá del ejercicio de deconstrucción del proceso, y de los terrenos de reflexión e investigación que el tema de la herencia de los escritores permite entrever, ¿cómo actuar cuando una serie de circunstancias pone al pariente o al crítico frente a esa página en blanco de un legado por construirse? Teniendo en cuenta las concepciones de la propiedad y del sujeto autor (también en esa esfera que se supone oculta: lo íntimo, lo familiar, lo sexual), muy perceptibles en estos casos, no es superfluo interrogarse sobre los pasos que llevan a una eventual divulgación o, más simplemente, a una preservación. Sin caer en el "biodrama" ni en la confesión privada -tampoco hay que substituirse al sujeto de estudio-, preguntémonos ¿qué elecciones de organización, qué modos de publicación, qué hipótesis generales, sobre el escritor y sobre el fondo legado, son operativas en las diferentes decisiones tomadas por los herederos y por los especialistas que se ocupan de esos papeles? ¿Qué sentido tiene preservar, preservar adónde, preservar cómo? ¿Qué publicar, qué "mostrar" de lo íntimo y de lo inacabado? ¿Qué operaciones y apropiaciones se llevan a cabo con el autor, con su figura, con su obra, al avanzar en ese camino, a menudo arduo pero también apasionante? ¿Y cómo comunicar ese material, o no comunicarlo, en un medio estrecho de investigadores sobre temas afines? 
A esta reflexión cabe incluirla en la perspectiva de la crítica genética. Es hoy un lugar común señalar que esta corriente crítica ha ido ampliando su campo de observación y que, actualmente, se trata no sólo de estudiar el proceso de creación en el sentido estricto, sino también una gama de fenómenos que lo preceden y rodean (el universo mental del escritor, sus lecturas, comentarios en los márgenes de sus libros, correspondencia, anotaciones de todo tipo, proyectos frustrados), así como los que lo prolongan: condiciones de publicación por herederos, características de las reediciones, adaptaciones teatrales y cualquier otro avatar que complete, más allá de la edición princeps, el texto de referencia estudiado. ${ }^{3}$ Por lo tanto, en el caso Saer que voy a comentar aquí, las dos ampliaciones así designadas merecen atención: por un lado, la masa de documentos producidos al margen del trabajo directo sobre la obra édita, por el otro la manera en que estos documentos, de algún modo paradójico, prolongan dicha obra si son editados. Puesto que proyectamos la publicación del material inédito del escritor, partimos de la base de que las decisiones aferentes a esa publicación implican, quiérase o no, una intervención en el proceso de "creación" y son por lo tanto problemáticas. Poco a poco hemos ido tomando conciencia del sentido de cada acto y gesto (organización, catalogación, tipo de transcripción y de publicación): este texto pretente presentar las condiciones de constitución del Fondo -el trabajo realizado- y plantear los interrogantes que se imponen sobre el trabajo por realizar (y que podría, claro está, ser revisado y reestructurado por otros luego). La única respuesta al "relato" de la herencia, la única manera de manejar la serie implícita y explícita de problemas planteados en la tradición evocada en los párrafos precedentes es, me parece, a la vez la transparencia y el espíritu crítico.

\section{El relato}

Alrededor de dos años después del fallecimiento de Juan José Saer (11 de junio del 2005), los que habíamos trabajado sobre los manuscritos

\footnotetext{
${ }^{3}$ Ver conferencia de Almuth Grésillon citada y comentada por Philippe Willemart, Critique génétique : pratiques et théorie, París, L'Harmattan, 2007, pp. 133-134, o las afirmaciones de Louis Hay al respecto: “...desde la primera palabra, aunque sea solitaria y única, la escritura se afirma en tanto que proceso estético. La constatación nos propone un argumento esencial para considerar que el terreno de la genética se abre en el instante de las primeras inscripciones y no, como pudo decírselo, en el momento en que el manuscrito empieza a volverse texto." Louis Hay, "Réflexions sur la discipline", traducción mía, Olga Anokhina y Sabine Pétillon (eds.), Critique génétique. Concepts, méthodes, outils, Saint-Germain-la-Blanche-Herbe, Imec éditeur, 2009, p. 29.
} 
de Glosa y El entenado para la edición Archivos (Julio Premat, Diego Vecchio, Graciela Villanueva), ${ }^{4}$ junto con Sergio Delgado, acordamos con Laurence Gueguen, su compañera y albacea de la obra, consultar los papeles dejados por él y tratar de ver cómo se los prodría ordenar y preservar. Rápidamente, tres otras investigadoras, se asociaron al grupo (Mariana Di Ciò, Valentina Litvan y, en una primera etapa, Pénélope Laurent). Empezó lo que terminaría siendo una larga trayectoria de trabajo y un proyecto de investigación de envergadura, intitulado Fondo Saer. Archivos, memoria, crítica, que contó con el apoyo de varias instituciones en Francia (Université Paris 8, Université Bretagne-Sud, Institut des Amériques, Fondation argentine) y que, en algún momento, estableció una colaboración con un proyecto paralelo dirigido por Miguel Dalmaroni y aprobado por el CONICET en Argentina.

Tres fuentes de documentos existían en el escritorio de ese departamento de la rue du Commandant Mouchotte, al lado de la estación de tren Montparnasse, en el cual Saer vivió muchos años y escribió la última parte de su obra. Por un lado, los papeles amontonados en una pequeña mesa de trabajo, enmarcada por una biblioteca con diccionarios, libros de filosofía, libros de psicoanálisis y frente a la biblioteca de literatura universal. Se trataba de los documentos utilizados para la escritura de $L a$ grande, novela en la que Saer estaba trabajando en el momento de su muerte. Los textos autógrafos encontrados fueron integrados en el conjunto del Fondo y el resto de los documentos forman parte de los anexos del mismo (se podrá consultar la lista al final de este texto).

Por el otro, una serie de copias de salvaguarda en disquetes informáticos, reproducían el contenido de la computadora con la que Saer trabajaba ocasionalemente, en particular para pasar en limpio manuscritos, y que utilizó para la última campaña de escritura del capítulo seis de La grande. La consulta de esos disquetes y de la computadora le permitió a Laurence Gueguen, en su momento, reconstituir junto con Alberto Díaz, el editor, la versión más finalizada posible de la novela, pero no había en ellos ningún otro borrador ni texto inédito.

Por fin, en un placard en el fondo del cual se encontraba una biblioteca de literatura argentina y latinoamericana, amontonados, en carpetas, bolsas, portafolios o dispersos entre publicaciones de todo tipo, Saer

\footnotetext{
${ }^{4}$ Juan José Saer, Glosa - El entenado, edición crítica y genética coordinada por Julio Premat, Cordoba-Poitiers, Alción-Archivos, 2010.
} 
guardaba buena parte de los cuadernos que utilizó, a la vez como libretas de anotaciones varias y como soporte de redacción de los textos definitivos. En las carpetas, particularmente desordenadas a pesar de repetidos intentos de clasificación, también había algunos borradores de obras éditas, y sobre todo una masa importante de papeles de trabajo o de pequeños textos inéditos.

Formalizar en un catálogo el contenido de todos estos documentos nos obligó, primero, a una lectura minuciosa si no exhaustiva, para comprender el funcionamiento del archivaje (caótico, como puede verse), y el del proceso de escritura, que, afortunadamente, ya conocíamos en parte gracias al trabajo sobre los manuscritos de Glosa y El entenado. Luego, a intentar una organización de los cuadernos, aproximadamente cronológica y de los papeles sueltos (en y fuera de las carpetas), a la vez cronológica y genérica. El resultado es la identificación de sesenta cuadernos de formatos muy diversos, algunos de varias centenas de páginas escritas y otros casi en blanco. A partir de las carpetas existentes, ordenamos buena parte de las hojas sueltas, nueve carpetas de ensayos y afines, ocho carpetas en relación con la prosa, una carpeta de poesía muy voluminosa, y cinco carpetas con papeles varios (administrativos, por ejemplo). Excluimos del trabajo la correspondencia, que queda todavía por leer y clasificar.

Paralelamente a este trabajo, los herederos de Saer decidieron iniciar negociaciones para un depósito posible del Fondo en una biblioteca conocida por su fondo de escritores latinoamericanos, biblioteca que tiene medios suficientes para preservar el material y para ofrecer becas a investigadores, y que, además, pertenece a una universidad con la cual Saer fue estableciendo relaciones académicas en los últimos años: la Princeton University Library. Podrá consultarse en línea el catálogo establecido por esa institución, catálogo que, a pesar de algunas confusiones y omisiones, da una imagen de la importancia del Fondo y de su contenido detallado. ${ }^{5}$

Luego de la organización y la catalogación, la tercera etapa consistió en la digitalización, por vía fotográfica, del conjunto (alrededor de 8000 fotos fueron necesarias para preservar una copia integral) y en una progresiva transcripción del material inédito. En paralelo a este trabajo, proyectos personales de investigación empezaron a desarrollarse (las

${ }^{5}$ Juan José Saer Manuscripts, código C1393 (14 cajas). Catálogo consultable en: http:// findingaids.princeton.edu/. 
ponencias publicadas en las presentes actas reflejan un embrión de ese trabajo), así como una reflexión colectiva sobre las características del material, las posibilidades de organización y las perspectivas de edición.

Finalmente, y en esta etapa estamos hoy, se trata de preparar la edición de parte del Fondo, es decir de casi todo el material inédito. La publicación está prevista en la editorial Seix Barral y los tres volúmenes proyectados tendrían que empezar a salir el próximo año.

\section{Contenido y funcionamiento}

Como se puede deducir de la perspectiva elegida, cada paso del proceso arriba resumido supuso o supone una puesta en duda constante de lo decidido y un intento de medir las consecuencias de cualquier gesto definitivo. Por supuesto, la edición de inéditos es, en ese sentido, el momento más determinante. Ante todo, tomar en cuenta el estatuto peculiar de estos textos y de su posible recepción supone descartar una publicación tradicional (tipo: "cuentos inéditos" o "ensayos inéditos", etc.), e inventar otro tipo de organización. Para hacerlo, es indispensable un estudio somero de algunas características del Fondo, tanto materiales -una descripción que sugiera, ya, alguna perspectiva reflexiva-, como de su funcionamiento.

Comentemos primero algunas paradojas del Fondo Saer en su conjunto: por un lado, es un material abundante y excepcionalmente bien preservado; los manuscritos de la mayoría de los veintitrés libros publicados por el autor y una serie de documentos preparatorios pueden consultarse en él. Sin embargo, y por la especificidad del proceso de escritura de Saer -que ya pudimos analizar la edición Archivos-, no hay borradores, si entendemos borradores en su sentido más estricto: primeras versiones que van a ser reescritas y retomadas antes de llegar a la versión definitiva. En todo caso, sólo hay borradores de los inicios de las novelas, que son un espacio de duda y proliferación, y luego hay manuscritos que, a pesar de numerosas correcciones en ellos (y las que el escritor va a introducir antes de la edición definitiva, en la versión mecanografiada o en las pruebas de galera), no contienen por lo tanto las variantes que son el terreno privilegiado de estudio por parte de la crítica genética. Esta ausencia de borradores remite, claro está, a un proceso de escritura en el cual la fase preparatoria, de a veces muchos años, es crucial. 
Por otro lado hay un abundante material inédito que, en buena medida, no es un material estructurado (no son "cuentos", "novelas", "ensayos"). La falta de inéditos consecuentes (de novelas, en particular) se explica entonces por el peculiar mecanismo que lleva a una emergencia progresiva e incierta que, cuando se define como viable, termina siempre en la textualización completa y en la edición. Algo similar podría decirse para entender que algunos textos muy trabajados y, valga el juicio discutible, excelentes, hayan quedado inéditos: por su formato atípico, por no haber sido escritos en el marco de una estructura orgánica más amplia, no encontraron un lugar natural en un libro. Recuérdese que fue necesaria la propuesta de organizar una antología en 1984 (Juan José Saer por Juan José Saer), ${ }^{6}$ para que textos como "Atridas y Labdacidas", "Filocles" y "Las instrucciones familiares del letrado Koei", ya escritos, se publicaran: la antología permitió la heterogeneidad. Puede pensarse que, así como Saer terminó incluyendo algunos textos de los cuadernos en la sección "Apuntes" de La narración-objeto (textos a veces escritos veinte años antes), parte del fondo inédito hubiese sido, en un futuro hipotético, enmarcado en un proyecto de edición satisfactorio para el escritor y por lo tanto dado a conocer con su firma.

Sea como fuere, hay una masa de documentos, asociados o asociables a libros publicados y que, en algún momento y si hay críticos disponibles para ese meticuloso trabajo, podría dar lugar a la constitución de dossiers genéticos, como pudimos hacer con las dos novelas arriba mencionadas. Al juntar todo ese material se constituiría lo que la crítica genética denomina el avant-texte de una obra: anotaciones, borradores, primeras textualizaciones, versiones tapuscritas corregidas, etc. Dicho sea de paso, en el ejemplo de Glosa y El entenado, descubrimos, años después y a la hora de revisar nosotros el material disponible, que Saer por descuido, olvido o involuntaria reticencia, sólo nos había transmitido parte de los documentos sobre esos libros: los dossiers publicados por Archivos son incompletos, lo que quizás no les quite pertinencia a su edición y al estudio llevado a cabo sobre ellos, pero la anécdota demuestra, si fuese necesario, el carácter aleatorio y relativo de los dossiers en sí y de las conclusiones a los que éstos dan lugar.

En esa perspectiva y en paralelo ¿qué estatuto atribuirle a lo demás, es decir al conjunto de anotaciones, borradores incompletos, reflexiones, reacciones de lectura, citas, ensayos, hallazgos, ideas inconexas, que

${ }^{6}$ Juan José Saer por Juan José Saer, Buenos Aires, Celtia, 1986. 
constituyen la mayor parte del material encontrado en el departamento de Saer? Si todo avant-texte es una reconstrucción hipotética, por parte del crítico, de un proceso de escritura ${ }^{7}$, de lo que se trataría es de reconstruir un gigantesco avant-texte, no de un libro específico, sino de la totalidad de la obra. Una especie de "preconstruido genético", es decir el conjunto de operaciones de escritura y lectura que acompañaron el trabajo directo sobre un segmento pero que, puede postularse, son operaciones en las que las características generales del proyecto literario se fueron definiendo, reaccionando y adaptando una voluntad de obra y una serie de elecciones iniciales (válidas desde En la zona), a los diferentes accidentes y peripecias de una vida personal, de un período histórico y literario, y de la dinámica intrínseca de una trayectoria creadora de largo alcance. En ese sentido es interesante que los bibliotecarios que clasificaron el material en la Princeton Public Library hayan elegido, en contra de la organización provisoria que nosotros les habíamos propuesto, un principio que ordena lo inédito en función de lo édito, o sea de la bibliografía pública del escritor, y en función también de una cronología que, se supone, subyace en la edición progresiva de esos libros. Una rápida mirada al Fondo muestra que ambos principios (organización alrededor de libros éditos y cronología ordenada), contradicen ampliamente las características de lo encontrado en el escritorio de la rue du Commandant Mouchotte.

Los documentos inéditos forman parte de esa fase difícil de delimitar de preparación, son todo lo desechado pero también todo lo que permitió, de algún modo que se nos escapa, llegar a las versiones definitivas publicadas. Por lo tanto, sin ser borradores de esas obras, cabe leer el conjunto como un borrador de lo édito. El Fondo es el dossier genético de toda la obra. En ese sentido, el conjunto inédito es a la vez un "pre-texto" - o una "pre-obra"- de lo publicado, frente a lo cual se sitúa entonces en una posición de "otra obra": reflejo, promesa y deformación borrosa, y en la de un texto autónomo: es otro avatar

\footnotetext{
${ }^{7}$ El concepto de avant-texte fue uno de los que la crítica genética definió primero (a partir del precursor Jean Bellemin-Noël y su libro Le texte et l'avant-texte. Les brouillons d'un poème de Milosz, París, Larousse, 1972). Propongo una definición actualizada y clara, la de Daniel Ferrer (en Logiques du brouillon, París, Seuil, 2011, p. 85), quien califica al avant-texte de "modelo de los modelos" para la crítica genética: "[El avant-texte] constituye una modelización propuesta por el crítico de los datos empíricos o más exactamente, de lo que el crítico selecciona en un conjunto ilimitado de datos" (traducción mía).

${ }^{8}$ Expresión de Henri Mitterand en un estudio sobre Zola, citada por Daniel Ferrer, ibid., p. 93.
} 
en el sistema de amplificaciones y variantes. El Fondo circula en una esfera peculiar de cara a la obra édita, pero forma parte de ella, o de una definición revisitada de obra; la perspectiva es la de la obra en tanto que espacio de trabajo y no como objeto terminado. ${ }^{9}$

Pasando a un intento de establecer una tipología del material, digamos que la simple y llana descripción de los papeles impone una serie de relativizaciones de cualquier deslinde tipológico estricto. Siguiendo ejemplos canónicos, como el de Flaubert, sería tentador partir de una clasificación por soporte (cuadernos/carpetas/hojas sueltas) y una periodización a partir de la cronología de los cuadernos; sin embargo, es necesario matizar la operatividad de dicho principio. Algunos cuadernos contienen materiales muy diferentes, escritos en fechas alejadas, otros son coherentes, otros están casi totalmente en blanco.

Más que una clasificación del material, la descripción de la relación que el escritor estableció con él, cómo lo organizó o no lo organizó, es, me parece, un primer paso analítico significativo, aunque en regla general la descripción dé como resultado principios encontrados cuando no contradictorios. Por un lado, a lo largo de los años constatamos un intento de ordenar el conjunto y de funcionar con una tipología de cuadernos estricta. Efectivamente, aparece una clasificación efectiva o incipiente, que supondría que hay cuadernos dedicados exclusivamente a manuscritos de una obra libro determinada, otros a la escritura de poesía, o a traducciones de poesía, cuadernos para géneros periféricos (guiones de cine, teatro), libretas de viaje, cuadernos de notas e ideas generales que no se inscriben en el trabajo de un libro preciso y que se guardan muchos años (uno de estos cuadernos, que hemos denominado "cuadernos núcleo", abarca aproximativamente veinte años de producción). Muchos gestos apuntan en esa dirección, siendo el más espectacular la preparación de los cuadernos, trece en total, para $L a$ grande: desde el 95, fecha de los primeros borradores del incipit de esa novela, Saer guardaba una serie de cuadernos, todos similares (marca, formato, número de páginas), preparados para una redacción futura, personalizados con líneas diferentes hechas por el escritor, a veces con una foto personal abrochada en la solapa interior. Algunos de esos cuadernos quedaron en blanco, manteniendo, inclusive, una numeración

\footnotetext{
${ }^{9} \mathrm{Cf}$. Bernihld Boie et Daniel Ferrer, "Les commencements du commencement", en Genèses du roman contemporain : incipit et entrée en écriture, París, CNRS, 1993, p. 8. Sobre la definición de "obra" como proceso y operación, ver también Anne Herschberg-Perrot, Le style en mouvement. Littérature et art, París, Belin sup, 2005, pp. 134-146.
} 
manual de las páginas todavía no escritas. Otro ejemplo: el cuaderno dedicado a los borradores del libro de cuentos Lugar (2000). En él una diagramación personal integra etapas de trabajo que, en otros momentos, estaban separados en soportes distintos: en la parte inferior, en el lugar habitual de una nota infrapaginal, se encuentran las anotaciones varias que acompañaban, en papeles sueltos y marginalias, el trabajo habitual de escritura. La hoja se adapta al tipo de trabajo y se organiza para facilitar su desarrollo.

En otro orden de ideas pero en la misma perspectiva, no se puede sino recordar el cuidado por los cuadernos (que muy frecuentemente integran una "carátula" con el nombre y la dirección del escritor -ya que temía perderlos-), las referencias a los propios cuadernos en las notas, como objetos de valor reconocido, y también la precaución de buscarlos y transportarlos desde Santa Fe a París, como lo hizo con muchos de ellos. O la circulación de citas de un cuaderno a otro, releídas, por lo tanto, y recopiadas: por ejemplo un sueño sobre Nabokov que se encuentra en un cuaderno en el que figura el manuscrito de $L a$ pesquisa y en otro, un cuaderno "núcleo":

"Quizás nuestra sociedad obliga hoy en día al artista a entregarse a la vulgaridad, igual que hace un siglo obligaba a los poetas malditos a abandonarse al ajenjo" (Dicho por Nabokov en un sueño de J. J. S.) Noche del 14 al 15 de marzo de 1995.

El modelo flaubertiano actúa y podemos presuponer una puesta en escena privada de la escritura: uso de papeles y tintas de colores variados, elección de cuadernos de marcas y formatos inhabituales, tendencia fuerte a pasar a máquina varias veces el mismo texto, cuidado en la redacción de los manuscritos lo que les da una legibilidad cercana a una autoedición. Los cuadernos son el lugar en que se refleja y se piensa el trabajo del escritor, en el que se lo define en tanto que tal, más allá de la publicación o la circulación. Evidentemente eran objetos importantes, si no sacralizados. Un texto inédito habla del deseo de escribir, como quien dice de hacer el amor o de comer: deseo de estar en esa situación, ante esos papeles. Cito el comienzo:

Por el gusto de escribir algo: después de muchos días de silencio escritural me ha asaltado, en el baño, mientras me lavaba las manos antes de irme a acostar, el deseo de estar, a la luz de la lámpara, escribiendo. Deseo de escribir; no de decir algo. Pero deseo, también, de escribir en tanto que escritor: sin que ninguna razón, como no sea el deseo de estar a la luz de la lámpara, escribiendo, haya motivado mi acto. Mecerme en el equilibrio infrecuente y perecedero de la mano que va deslizándose 
de izquierda a derecha, oyendo los rasguidos de la pluma sobre la hoja del cuaderno, victorioso por el hecho de haber comprendido por fin que el deseo de escribir es un estado independiente de toda razón y de todo saber...

En contrapunto a lo expuesto, el sistema, constantemente actualizado, está puesto en duda por una circulación caótica de materiales que desmiente los principios elegidos. Hojas arrancadas de cuadernos que terminan en carpetas heterogéneas, cuadernos abandonados, cambios en la especialización de los cuadernos, comienzos de novelas en cuadernos a veces elegidos sin lógica aparente, etc. Los principios de organización reflejan, por lo tanto, una intención más que anuncian un resultado: la muy estricta preparación de los cuadernos para La grande son como una muralla de resguardo ante las amenazas de la dispersión. En este caso, la ambición y la amplitud del proyecto entonces comenzado presuponen un trabajo previo estricto para poder ser llevado a cabo. En reglas generales, la voluntad de orden y de coherencia funciona como una autoinstrucción que limita las fuerzas centrípetas de la escritura y que tiende a dibujar un ideal de control. De más está decir que en las carpetas se constata también un intento de ordenamiento (carpeta de poesía, carpeta dedicada a tal o cual proyecto de textos breves), pero la facilidad de manipulación y desplazamiento parece haber acentuado la desorganización sistemática. Sin embargo, si observamos de cerca el contenido, las hojas sueltas, esos papeles proliferantes, desordenados, cobran a su vez la forma inestable de otro tipo de cuaderno.

Si queremos llevar a cabo una tipología descriptiva del material, más que el tipo de soporte (cuaderno/carpetas) y la disposición en la que estaba el material (disposición voluntaria e involuntaria), son, consecuentemente, el tipo de utilización y la relación establecida con el trabajo de escritura los que permiten avanzar en una organización lógica del conjunto. Organización que, por lo tanto, será virtual y no material. Dicho esto, un esbozo de orden tipológico por tipo de contenido y, por lo tanto, de uso:

* Material prerredaccional, cuyas fronteras son por definición imprecisas: anotaciones de frases, instrucciones, esquemas, lecturas sobre aspectos abarcados por el texto que se está escribiendo, borradores y tanteos numerosos de las primeras frases de las novelas, etc.

* Manuscritos, precedidos muchas veces por "falsas partidas", pero sin que haya, como dijimos, primeras versiones ni primeros borradores. 
Encontramos manuscritos completos o parciales de nueve novelas y de la mayoría de cuentos, ensayos y poemas publicados por el escritor. También manuscritos de muchas entrevistas (sobre todo hasta comienzos de los noventa), cuidadosamente corregidas.

* Poemas inéditos, a veces en papeles sueltos o en medio de una página aparentemente dedicada a preocupaciones diferentes. Otros, corregidos y pasados en limpio. Cabe señalar la importancia de la escritura de poesía, en particular en los años sesenta y setenta (alrededor de 150 poemas inéditos).

* Reflexiones metaliterarias. A la vez largos ensayos estructurados, corregidos, pasados a máquina y sin embargo inéditos, y comentarios más o menos extensos que funcionan como autoinstrucciones dentro de una poética o de una concepción de la literatura. La masa de ensayos de juventud es impresionante, sobre todo comparándola con el escaso número de ellos que se publica posteriormente (ocho textos de los años 60 en El concepto de ficción, 1996).

* Textos inéditos inclasificables, entre la descripción epifánica de un determinado momento hasta breves secuencias narrativas.

* Proyectos de libros o de relatos, la mayor parte inacabados, muy pocos en comparación con lo édito.

* Notas de lectura diversas, desde el comentario sobre una idea o un autor hasta el copiado de varios párrafos, una frase, o inclusive una expresión.

* Muchas ideas, hallazgos verbales, aforismos, coloquialismos, o sea una especie de acumulación de material verbal e imaginario, del que no podemos decir si correspondía a una simple anotación de lo efímero o, a veces, a un trabajo específico en vías de un texto determinado.

* Anotaciones íntimas, en particular relatos de sueños, sobre las que habría que señalar, más que el pudor, el carácter aparentemente utilitario que parecen tener: narrar un sueño se asimila a una práctica de escritura o a la confrontación con un imaginario, no a una confesión.

* Traducciones, en general de poesía (un cuaderno entero le está dedicado y hay otras muchas dispersas), pero también de prosa literaria o ensayística. En la mayoría de los casos la traducción formaba parte 
de un entrenamiento a la escritura, y no necesariamente de un proyecto de publicación.

* Algunos textos de otros géneros: guiones o resúmenes para el cine, un par de intentos de escribir obras de teatro.

* Por fin, y esto corresponde con las contradicciones del sistema, los cuadernos y hojas sueltas también servían, digamos de libreta de anotaciones para la vida cotidiana (nombres de productores de vino y citas con algún plomero), y de hoja borrador para textos administrativos.

Lo que precede dibuja un verdadero mapa del trabajo de un escritor: inventar, decir, imaginar; leer como modo de leerse en los otros; soñar; discutir; encontrar y hacer sonar agudezas y aforismos, experimentar otros géneros, traducir. Un taller de creación en el cual vislumbramos, retomando la terminología de la crítica genética, trazas a la vez de endogénesis y de exogénesis, la mayor parte de las veces inextricablemente mezcladas. ${ }^{10}$ A modo de ejemplo ilustrativo, copio dos páginas de uno de esos cuadernos "núcleo", utilizado desde fines de los 80 al 2001:

El ir y venir por la autopista, entre la ciudad y Rosario, de los colectivos de todos colores.

****

El texto "Se podría..." Entrelazamiento de relatos de todo tipo, escritos en forma conjetural e impersonal, que es el modo expresivo de lo imaginario. Los relatos, de distinta extensión, varias o muchas páginas, media página, un par de renglones, un renglón, no estarían sometidos a ningún tiempo narrativo ni estructura fija, irían apareciendo los relatos con sus variantes, sus ecos culturales, etc. Este texto suplantaría el "libro de cientos", sería un modo nuevo de concebir las historias cortas. ****

Hay que advertir que en muchos autores el citado aumento de espiritualidad y la independencia de la ciencia no están separados, sino estrechamente ligados (J. Ferrater Mora. Art. occamismo)

\footnotetext{
${ }^{10}$ Sendas definiciones dadas por Pierre-Marc de Biasi: "Llamaremos entonces endogénesis el proceso por el cual el escritor concibe, elabora y transfigura la materia pretextual sin recurrir a documentos o informaciones externas, por simple reformulación o transformación interna del estadio pretextual anterior"; "La exogénesis designa cualquier proceso de escritura dedicado a un trabajo de investigación, de selección y de integración que concierne informaciones provenientes de fuentes exteriores a la escritura." Pierre-Marc de Biasi, "Qu'est ce qu'un brouillon ? Le cas Flaubert : essai de typologie fonctionnelle des documents de genèse", puesto en línea el 19 de enero del 2007. Disponible en: http:// www.item.ens.fr/index.php?id=13366. Traducciones mías.
} 
Guillermo de Occam (1298-1349) fue llamado Venerabilis inceptor (el "Venerable principiante"), a causa de no haber enseñado como doctor, aun cuando algunos han interpretado este título honorífico como parte de Venerabilis Inceptor invectissimae scholae nominalium ( "el venerable fundador de la nunca derrotada escuela nominalista"). $* * *$

Puede juzgarse la pertinencia de sus ideas religiosas por los programas de televisión que prefieren.

Automatismos mentales. $* * *$

Conocer íntimamente a un hombre a través de lo que subraya en los libros.

$* * *$

El padre de Max Ernst, pintor aficionado, pintó un día el jardín de su casa. Empezó al aire libre y terminó en su taller. El cuadro representaba un sector del jardín con un gran árbol en el medio. El padre de Ernst borró el árbol del cuadro por parecerle que el cuadro quedaba mejor sin él. Después arrancó el árbol del jardín para que se pareciese al cuadro. $* * *$

El número 18 como pensamiento - la división en fracciones; la imagen visual de la cifra - abstracción de los 18 . Se piensa en el signo o cifra, nunca en la cantidad, etc...

$* * *$

Refutar en Lo imborrable el libro de la República. $* * *$

... real para sí mismo y fantasma para los otros... $* * *$

Les Lettres de Monteverdi - Flammarion principios de 1990 $* * *$

"Couleurs de la Cité Céleste" d'Olivier Messiaen ****

"Une bonne phrase de prose doit être comme un bon vers, inchangeable, aussi rythmée, aussi sonore" (lettre à Louise Colet)

Cuando varias personas emplean la palabra "poético", ¿se forman todos la misma representación?

Reconocemos en la serie una autoinstrucción para Lo imborrable, proyectos (texto "Se podría", el 18 como pensamiento), notas de lectura (cartas de Flaubert, Ferrater Mora, anécdota sobre el padre de Max Ernst o sobre Guillermo de Occam), referencias bibliográficas y musicales (cartas de Monteverdi, Messiaen), agudezas (religión y televisión, subrayados, real y fantasmas), impresiones perceptivas (los colectivos), etc. 
En el registro de la intimidad, digamos que, aunque el tono de estos "papeles de trabajo" es constantemente distanciado, incluso refiriéndose a estados de ánimo o a sueños, algo sucede en ese nivel cuando los leemos. Fetichismo o efecto de autor, lo que pudorosamente Saer excluyó de su obra y de su figura pública, adquiere mayor visibilidad a partir del Fondo. El autor tiene más, digamos, corporeidad. Es decir que un fondo de este tipo genera una impresión de acercamiento supuesto a un "personaje de autor" más vívido, fuerte, presente y renovado, en comparación con el conocido hasta entonces. También en términos de figura de autor, la edición tomará, quiérase o no, una posición en el retrato propuesto.

Volviendo a la perspectiva general, y es una primera conclusión del recorrido realizado, hay una diferencia esencial entre el material que contiene el archivo, e inclusive los criterios de organización que puedan elegirse para ordenarlo, y una descripción sintética y tipológica satisfactoria.

\section{Cronología}

El Fondo contiene una temporalidad, una historicidad, que no es lineal (no es material de escritura de una novela determinada), sino la de un proceso más heterogéneo, confuso y variado. En un primer nivel, el material nos propone un recorrido paralelo a la de una periodización de la parte visible, es decir lo editado; y permitiría, en sus modificaciones y constancias, el estudio de un proyecto, de una manera de ser escritor (un estilo de escritura), y, por qué no, de una manera concebirse como escritor de cara al campo literario, a la recepción, a las expectativas sociales y culturales de lo escrito.

Al Fondo puede pensárselo entonces a partir de las etapas de evolución, paralela, de lo publicado, por un lado, y del tipo de material preparatorio existente, por el otro. Desde este punto de vista, notamos que hay material de la juventud abundante, en particular del período argentino de escritura (1957-1968), aunque faltan manuscritos de las obras de esos años (hemos tomado conocimiento de la existencia de algunos cuadernos de este período que se encuentran en Argentina, que intentaremos digitalizar). Por otro lado, la costumbre de guardar sistemáticamente los cuadernos se refuerza y cristaliza en el último período, o sea que podemos estar relativamente seguros de que todo el material de los años 90 y 2000 ha sido conservado. 
Revelando sus obsesiones temporales pero también llevando a cabo la escritura secreta de una autobiografía intelectual, Saer fechaba sistemáticamente los textos, lo que favorece una ubicación en la cronología y refleja su propia preocupación por lograr situarse, en las relecturas eventuales, en una historia privada de su escritura. Porque la consulta sistemática del Fondo y el tipo de uso por parte de Saer muestran una conciencia aguda de la cronología; citemos por ejemplo estas notas sobre su recorrido, que no estaban destinadas a su publicación:

En el 68, obtuve, un poco por casualidad, una beca del gobierno francés y me vine a Francia por seis meses - me quedé 26 veces más, es decir trece años ya. Volví dos veces a Argentina, en 1971 (dos meses y medio) y en el 76 (casi dos meses). Yo creo que usted tiene ya las fechas de redacción de todos mis libros, le preciso algunos datos; El limonero fue escrito entre 1963 y 1972; en 1967, por septiembre-octubre quizás, escribí Cicatrices prácticamente de un solo envión, en unas 25 noches, desde las nueve, nueve y media hasta el alba. La venía pensando desde hacía cuatro o cinco años hasta que me decidí. Los cuentos de Unidad de lugar son del 65-66; había dos o tres más que finalmente dejé fuera. Los Argumentos los escribí entre 1969-1975 (la mayor parte son del 69 al 72; es decir son las primeras cosas, junto con algunos poemas, que empecé a escribir en París; los años 70, 71 y 72 fueron muy productivos; en el 73 empecé Nadie nada nunca y la terminé en febrero de 1978. El entenado la empecé creo, a fines de 1978 y todavía está en veremos, aunque bastante bien encaminada. Un buen envión bastaría.

El Fondo permite llevar a cabo por lo tanto una periodización tomando en cuenta el tipo de trabajo prerredaccional y el uso de la anotación en cuadernos y papeles sueltos. Esta periodización coincide en grandes líneas con la periodización manejada por la crítica saeriana, profundizando sus motivaciones y justificaciones. Si combinamos los dos criterios (tipo de trabajo de escritura y datación) determinamos por lo menos tres grandes períodos o tres momentos diferentes:

1) El material de los años sesenta: sobreabundancia de dos tipos de textos: la poesía y el conjunto de ensayos, notas metaliterarias y de lectura. O sea que lo publicado entonces (después de algunos poemas de primera juventud, en esa época Saer publica sólo relatos), no corresponde con lo producido. Esta escritura de poesía y de ensayo es interpretable: el narrador que viene de la poesía y que va construyendo, ya, el que será su único libro de poemas, libro multiforme que se irá transformando en cada reedición. Y el narrador que, sotto voce, practica el ensayo como género dominante y como posición preescrituraria, haciendo de la reflexión sobre la literatura el espejo evidente de la propia obra (la 
estrategia es leer escribiendo en tanto que herramienta para definir un proyecto) pero también instalándose en una posición íntima de polémica ante los otros libros, posición que, después de todo, será una marca de la producción ensayística de Saer. La permanencia en Argentina, con su lote de intercambios y polémicas intelectuales, la inserción en grupos, los debates y tensiones del campo literario argentino y santafesino, pueden también justificar esta sistemática "toma de posición" o, podemos pensar, esta constante "puesta a punto" de una posición.

2) El material de los años setenta y comienzo de los ochenta. En este caso lo que domina es la escritura, variada y polimorfa, de poesía, ficción, escenas, aforismos, etc. Período, ya no de afirmación, sino de creatividad, iniciado con la gran reorientación del proyecto que pudo suponer Cicatrices. De creatividad pero también de búsqueda de un tono, de un tipo de argumentos, de formas; es en este período en el que aparece la mayor parte del material no explotado o no desarrollado, incluyendo, excepcionalmente, proyectos truncos, tanteos de libros posibles. Por ejemplo un libro sobre el medio literario de la ciudad, de tonalidad paródica y bajo la forma de presentaciones biobibliográficas de personajes conocidos de la obra (Círculo de octubre). O una novela panorámica (Continuo) en donde debían aparecer centenares de personajes y todas las peripecias de los relatos anteriores (lo que parece prefigurar La grande); otra novela, de la cual sólo quedan dos borradores de incipit con Barco protagonista, varios libros de ensayos (literarios o sobre noticias policiales), alguno de poesía, etc. Pero no sólo encontramos callejones sin salida, sino los primeros pasos de buena parte de la obra posterior: esbozos de un libro de relatos intitulado Mimetismo animal (del cual debía formar parte la protoversión de El entenado) que, mucho después, se convertirá en Lugar, larga gestación de Glosa y de su segunda parte, sombría, primero intitulada El intrigante (prototexto de La grande) y que será luego Lo imborrable, recuperación de un proyecto de 1961 para la redacción de La ocasión, etc.

3) La afirmación posterior. Con los años, el material inédito se reduce notablemente, en todo caso se reduce el material que no está puesto, directamente, en la perspectiva de la publicación. Menos tanteos críticos y teóricos para situar la propia obra, menos tanteos en busca de una idea de novela o de libro. En cambio, se impone el uso de libretas de viaje, como una práctica asidua y, en alguna medida, como un género nuevo.

Estas divergencias, fuertes, pueden dar a lugar a múltiples comentarios. Uno de ellos concierne la aparente unidad o al menos coherencia 
del proyecto, visto desde su final (o al menos desde las novelas mayores de los años ochenta, desenlace del segundo período de alguna manera). La crítica genética demostró que en la redacción del Ulises de Joyce había tres etapas distintas, con postulados literarios divergentes, pero uniformizadas por una serie de correcciones posteriores que borraron, en particular en los primeros capítulos, el aspecto convencional de las campañas de escritura iniciales, ${ }^{11}$ algo similar podría decirse sobre el conjunto de la obra de Saer, visto a partir de lo inédito. Al mismo tiempo, y esto sucede con el material prerredaccional de cualquier libro, la consulta del Fondo modifica la impresión de coherencia y uniformidad de una obra o de un proyecto: el Fondo le agrega a la visión de lo publicado por Saer el saber de lo aleatorio, la conciencia de los caminos no recorridos o de las ideas no desarrolladas. Es todo lo borrado, lo tachado, lo que no dio lugar a una escritura triunfante (o no tuvo tiempo para hacerlo). ${ }^{12}$

Tres posiciones distintas, que podrían ser las de tres escritores diferentes, se esbozan; lo singular son los mecanismos de naturalización y de uniformización que, a posteriori, vuelven menos visibles los cambios y las distorsiones del proyecto inicial. Tres períodos que tienen que ver, de manera directa, con una serie de acontecimientos sociales y personales (entrada en literatura, contexto santafesino, partida a Francia, marginalidad y desterritorialización, reconocimiento en los 80, etc., etc.). El cruce de este material con los libros editados, lleva a apreciar el peso de algunos accidentes exógenos, ${ }^{13}$ como pudieron serlo el exilio en Francia, la dictadura, el retorno en los 80, las lecturas desde la universidad de sus novelas, el menemismo, la literatura llamada "postmoderna", el reconocimiento del público alrededor de La pesquisa, etc.

La posición de Saer frente a ese material también cambia, él va integrando progresivamente los manuscritos en sus ficciones. Por un lado, el Fondo en tanto que espacio múltiple y digresivo de trabajo,

${ }^{11} C f$. Daniel Ferrer, "L'écriture et l'accident", en Olga Anokhina y Sabine Pétillon, op. cit., p. 132.

${ }^{12}$ El concepto de tachadura (rature), definido y desarrollado por la crítica genética ( $c f$. Pierre-Marc de Biasi, La génétique des textes, París, Nathan, 2003, pp. 53-58), podría permitir, si se lo amplía metafóricamente, un análisis del funcionamiento de lo inédito frente a lo édito en Saer. Es lo que intenté hacer en un artículo en prensa, "Bocetos, borradores, esbozos. La otra obra de Saer", en Daniel Balderston (ed.), Crítica genética $y$ textos latinoamericanos, Pittsburgh, Revista Iberoamericana.

${ }^{13}$ Cf. Daniel Ferrer, "L'écriture...", op. cit., pp. 124-125. 
de invención y de documentación proliferante, pierde su fuerza a lo largo de los años, y se convierte mucho más en lo que la crítica ha llamado, a menudo con un matiz despectivo, el "taller" del escritor: un mecanismo, bastante eficaz, de producción. Y al mismo tiempo, en paralelo, el manuscrito, la ficción en suspenso o inacabada, el hecho en sí de anotar reflexiones y hallazgos, pasan a formar parte de la obra publicada (esto sucede en La pesquisa, en Las nubes, en La narraciónobjeto, en La grande, por lo menos). O sea, el manuscrito o la libreta personal, entran en la ficción cuando dejan, comparativamente, de ser lugares de incertidumbre, tanteos, multiplicidad incierta, pero también de vislumbres de lo escribible.

\section{Editar el Fondo}

Ahora bien, y volviendo al punto de partida, ¿en qué consiste lo problemático de una publicación de inéditos? Lo problemático no reside tanto en el consabido argumento, defendible pero también rebatible, que impondría respetar las decisiones editoriales que fue tomando el autor y no profanar el tabú de la creación, permitiendo la circulación impresa de textos en alguna medida privados, no corregidos o, peor aún, descartados de las publicaciones proyectadas. A pesar de cierta ideología académica que borra de un plumazo este argumento, no dudo de que, por supuesto, algo hay que responder a la objeción, a partir de una posición de respeto a reglas deontológicas elementales, las que suponen editar o hacer circular estos papeles marcando su estatuto singular, sin transformarlos, por poder y magia de un epígono póstumo, en equivalentes a los libros ya publicados -libros, eventualemente, con un evidente valor comercial-. También, alguna restricción posible a la edición de documentos de trabajo y de anotaciones íntimas tiene que ver con la frontera, tenue pero innegable, entre lo público y lo privado (entre lo publicado y lo que podríamos denominar lo "impúblico"); se trata de dos modos diferentes de socialización, que la edición de un fondo inédito trata como equivalentes, cuando a ojos vista no lo son. Después de todo, los escritores, muy a menudo, expresan reticencias ante la perspectiva de una transformación en material público de sus papeles privados. Un ejemplo célebre, la cita de Proust, en una carta a Sydney Schiff en 1922: "No me es muy agradable pensar que cualquiera (si todavía se interesan en mis libros), tendrá derecho a compulsar mis manuscritos, a compararlos con el texto definitivo, a inducir de ellos suposiciones que serán siempre falsas sobre mi manera de trabajar, 
sobre la evolución de mi pensamiento, etc." ${ }^{14}$ En ese sentido, se puede traer a colación una anotación equivalente del propio Saer, que en su juventud excluía la eventualidad de toda lectura o edición de sus cuadernos, pero que también, años más tarde, nos acompañó en el trabajo sobre los manuscritos de Glosa y El entenado. ${ }^{15}$

No, no se trata de esto, o no sólo. El problema es tomar en cuenta lo que antecede en la organización y publicación de lo que, ineluctablemente, va a instaurarse como un segmento más del sistema Saer; en última instancia como un "borrador" más -como lo son todos sus libros-, pero un borrador que, valga la tautología, fue borrado, que no se publicó en tanto que inestable versión definitiva. Es decir que, teniendo en cuenta las peculiares modalidades de funcionamiento y edición de sus textos, cualquier publicación nos lleva, no sólo a bambalinas de la creación en donde podríamos observar, fascinados o escépticos, las operaciones de engendramiento de la obra admirada, sino a textos que se ponen a circular como nuevas peripecias, nuevos segmentos, como otros libros del autor. Es un lugar común afirmar que, en lides de crítica genética, únicamente hay casos particulares; sin embargo parecería que la intervención en el corpus saeriano sería (será) más fuerte en este ejemplo que en otros, y la construcción de una operación editorial, tal vez más perceptible.

Poco a poco, certezas, si no principios, fueron imponiéndose. Ante todo, y en acuerdo con herederos y editores de Saer, no presentar lo inédito como un equivalente de los libros anteriores: la bibliografía de Saer en Seix Barral, con idéntica diagramación y tipo de ilustración, se acaba con Trabajos (2006), último libro que el escritor preparó. Por lo tanto, hay que integrar en el sistema paratextual y textual el caracter específico de esos textos, aun cuando sean, algunos de ellos, textos terminados y pulidos que, desde un punto de vista formal, no desmerecerían en el conjunto de la obra. Consecuentemente, rechazamos la idea de publicar una selección (lo más "interesante" de lo inédito), sino

\footnotetext{
14 “La pensée ne m'est pas très agréable que n'importe qui (si on se soucie encore de mes livres) sera admis à compulser mes manuscrits, à les comparer au texte définitif, à en induire des suppositions qui seront toujours fausses sur ma manière de travailler, sur l'évolution de ma pensée etc." Traducción mía. Citado por: Nathalie Mauriac Dyer, "Mille feuilles de l'écriture : les cahiers manuscrits 'au net' de Marcel Proust et la question editoriales", puesto en línea el 13 de marzo del 2007. Disponible en: http://www.item. ens.fr/index.php?id=76006.

${ }^{15}$ Sobre ese texto de juventud y sobre la integración progresiva de los manuscritos en la obra de Saer, véase mi artículo, publicado en este mismo número de los Cuadernos LIRICO.
} 
que partimos de la necesidad de reproducir en la medida de lo posible la heterogeneidad, la inestabilidad cronológica y genérica, así como lo fragmentario del material. Es decir que pensamos en la posibilidad de ofrecer una edición lo más completa posible -posible también en términos editoriales-. La lectura de los cuadernos y papeles de Saer presenta a la vez un interés estético, junto con el aliciente de mostrar las etapas, tanteos, gustos, callejones sin salida y atajos del trabajo de un escritor; para que este doble efecto sea perceptible, conviene no deformar su presentación y agrupamiento iniciales, aunque lo editado sea el resultado de una serie de decisiones algo arbitrarias. Por otra parte, y en el otro extremo, tampoco nos pareció pertinente sacralizar los papeles y atribuirles, en los modos de edición, un valor superior al de la obra édita. Es decir que optamos por una legibilidad del material, convencidos del doble valor arriba evocado y de la importancia simbólica, para la evaluación de la obra de Saer, de una edición que pueda tener cierta circulación.

Para terminar, una enumeración de las principales decisiones tomadas sobre la organización del material:

1) Presentar la edición como una serie o conjunto, pero separarla en tres tomos: un tomo de poesía, teniendo en cuenta la existencia de una carpeta, muy voluminosa, de poesía inédita, a menudo pasada a máquina, y que puede leerse como un borrador o marco para un solo libro, El arte de arrar $^{16}$. Un tomo de ensayos, porque en el Fondo encontramos varios proyectos de libros de ensayos ya preparados (con prólogo, índice, y múltiples versiones corregidas de los mismos textos), lo que demuestra que desde los años sesenta (como lo indica la contratapa de la primera edición de La vuelta completa, 1966), Saer no sólo escribía una cantidad abrumadora de ensayos, como dijimos, sino que varias veces intentó, sin éxito, editarlos. Por último, aunque seguramente vaya a ser el primer volumen publicado, el libro más extenso, en el que se incluira todo el material de escritura, los inéditos, los proyectos truncos, etc., y que se intitulará Papeles de trabajo.

2) Excluir lo que pertenece a los dossiers genéticos de la obra editada. A pesar del interés de algunas de esas páginas, su inclusión transfor-

\footnotetext{
${ }^{16}$ Ver al respecto las reflexiones de Sergio Delgado, quien se especializó particularmente en esta parte del Fondo, en "Retrato del joven poeta" (en Daniel Balderston-ed-, Crítica genética y textos latinoamericanos, Pittsburgh, Revista Iberoamericana, en prensa) y "El arte de hacer nuevos poemas" (volumen dedicado a Saer coordinado por Ilse Logie, Universidad de Sevilla, en prensa).
} 
maría la edición en una edición genética de inmanejable extensión. Una excepción, sin embargo, será la posible inclusión de parte del material preparatorio de La grande, por dos razones. La primera, por ser una novela incabada: la versión publicada es, también, un borrador incompleto. La segunda, para ofrecer al lector al menos un ejemplo del trabajo preparatorio de un libro específico, trabajo particularmente extenso y complejo en este caso, realizado en un período en el cual los inéditos son casi inexistentes.

3) Llevar a cabo una organización cronológica en el volumen Papeles de trabajo, pero una cronología laxa y aproximativa, es decir presentar los textos divididos en los tres grandes períodos ya definidos, que corresponden con un tipo de material y un tipo de trabajo distinto. En contradición con este principio, también pareció útil preservar la unidad de algunos cuadernos (los arriba señalados como cuadernos "núcleo" y "libretas de viaje"), que serán reproducidos integralmente, por sus especificidades pero también porque alguno de ellos cubre veinte años de producción. La edición va a alternar, por lo tanto, períodos amplios y cuadernos in extenso.

4) Enmarcar los textos con una presentación general del Fondo y una introducción descriptiva de cada conjunto (cuadernos, carpetas) precisando eventualmente contextos de producción, relación con otros textos, alusiones intertextuales y culturales, para que el lector sepa de dónde proviene lo que lee. Pero también excluir una anotación sistemática a pie de página, para evitar la intrusión constante de una voz, discurso o comentario ajenos a la escritura de Saer.

5) En el volumen de Ensayos, incluir todos los textos terminados, corregidos y estructurados que puedan integrarse en ese rubro, pero también algunas entrevistas, cuidadosamente redactadas y corregidas por Saer, inéditas o publicadas en medios muy confidenciales, y que incluyen información y juicios no repetidos luego por el escritor.

6) Si tomamos en cuenta que la denominación fija el proceso de creación y determina su génesis (es el après-coup que transforma el pasado), la elección de un título va a orientar el sentido, los procesos de constitución y el modo de funcionamiento de estos textos. Hemos elegido el título Borradores, por varias razones: el término no es ajeno al sistema semántico y lógico de la obra (inclusive en los títulos, como "A medio borrar" y Lo imborrable), anuncia el estatuto provisorio e inédito de lo publicado y, programáticamente, rechaza la idea de textos defi- 
nitivos, inscribiéndose en la corriente de la crítica genética que piensa la literatura a partir de las variaciones, lo inacabado, lo incompleto.

Copio el plan de edición en Seix Barral al día de hoy. Valga el plan, proyección hacia el futuro, como conclusión abierta para estas notas.

Plan provisorio de edición de inéditos del Fondo Saer.

Juan José Saer. Borradores.

Borradores I. Papeles de trabajo.

Papeles argentinos (circa 1958-1968)

Cuaderno núcleo (1963-1976)

La transformación de la obra (1969-circa 1986)

Cuaderno núcleo (mediados 80-2001)

Libretas de viaje (tres, 1982-2001)

La obra madura (circa 1986-2005)

Borradores II. Poesía.

Poesía inédita

Variantes de la poesía édita

Traducciones.

Borradores III. Ensayos.

Ensayos.

Entrevistas y textos autobiográficos. 